\title{
Comorbidities of Children with Intellectual Disabilities
}

\author{
Galiya S. Shubayeva ${ }^{1}$, Aisulu A. Tayzhan ${ }^{2} \&$ Dinar K. Baydosova ${ }^{2}$ \\ ${ }^{1}$ Department of Special and Social Pedagogy of Kazakh state women's teacher training university, Almaty, \\ Kazakhstan \\ ${ }^{2}$ Department of Special Education of Kazakh National Pedagogical University named after Abai, Almaty, \\ Kazakhstan \\ Correspondence: Galiya S. Shubayeva, Department of Special and Social Pedagogy of Kazakh state women's \\ teacher training university, Almaty, Kazakhstan. Tel: 77-27-233-4590. E-mail: galiya.sh@mail.ru
}

Received: February 24, 2015 Accepted: May 21, 2015 Online Published: June 13, 2015

doi:10.5539/ass.v11n16p168 URL: http://dx.doi.org/10.5539/ass.v11n16p168

\begin{abstract}
The article presents a review of literature about health of children with intellectual disabilities (ID), as well as the results of own research. Altogether 73 children with intellectual disabilities of primary school age were involved in research process. In process their health groups and characteristic of comorbidity were described. Revealed that the majority of children surveyed were from group II health $(63 \%)$ children with health group III accounted for $34 \%$ of children with health group IV-3\%. In 33\% of children with intellectual disabilities were observed these types of neurological disorders like hypertension-hydrocephalic syndrome (50\%), microcephaly (17\%), inorganic enuresis (13\%), hydrocephalus ( $8 \%$ ), convulsions (4\%), hemiparesis (4\%), asthenic-neurotic syndrome (4\%). If you stay at the co-morbidity in children with intellectual disabilities, they were registered in $48(66 \%)$ children, which is about $2 / 3$ of all surveyed. It is typical for children with intellectual disabilities and is consistent with the literature. The most frequent chronic inflammatory diseases, moreover observed heart disease, eye disease, deficiency conditions, genitourinary system diseases, musculoskeletal and digestive systems, hearing disorders, skin disorders. To sum up, the conclusions that requires special attention to the health of children with intellectual disabilities and comprehensive measures to strengthen it, as well as the need for further such research.
\end{abstract}

Keywords: children, intellectual disabilities, co-morbidity, physical health, health indicators

\section{Introduction}

Table 1. Disease prevalence and incidence of child population of Kazakhstan at the age of 0-14 years for 2013 by 100000 people

\begin{tabular}{lll}
\hline Disease & Prevalence & Incidence rate \\
\hline $\begin{array}{l}\text { Diseases of blood, blood-forming organs and certain disorders involving the } \\
\text { immune mechanism }\end{array}$ & 9204.3 & 4577.3 \\
$\begin{array}{l}\text { Endocrine diseases, nutritional and metabolic diseases } \\
\text { Mental and behavioral disorders }\end{array}$ & 2425.3 & 1114.4 \\
$\begin{array}{l}\text { Diseases of the nervous system } \\
\text { Diseases of the eye and its appendages }\end{array}$ & 773.4 & 132.8 \\
$\begin{array}{l}\text { Diseases of the ear and mastoid process } \\
\text { Diseases of the circulatory system }\end{array}$ & 6016.7 & 3096.4 \\
Respiratory diseases & 5180.2 & 3101.3 \\
Diseases of the digestive system & 3234.7 & 2477.7 \\
$\begin{array}{l}\text { Diseases of the musculoskeletal system and connective tissue } \\
\text { Diseases of the genitourinary system }\end{array}$ & 677.2 & 337.5 \\
Congenital anomalies (birth defects), deformations and chromosomal & 64576.5 & 55095.8 \\
abnormalities & 11424.1 & 6124.8 \\
Total & 1692.6 & 817.0 \\
\hline
\end{tabular}


Preservation and improvement of children health are a very important problem in the world today, including in Kazakhstan. This is due to environmental degradation, malnutrition, decreasing of locomotor activity etc., which leads to increased morbidity. In recent years, in the Republic of Kazakhstan, as in many countries of the world, there is a tendency in increasing of overall incidence in schools. In order to solve this problem are realized different reforms and programs, for example, the state health care reform program of the RK for 2011-2015 "Salamatty Kazakhstan" (The Ministry of Healthcare of the Republic of Kazakhstan, 2011).

Data on the Cause-specific Morbidity of children aged 0-14 years in Kazakhstan in terms of prevalence and primary morbidity are shown in Table 1 . Number of patients, consisting under medical observation at the end of 2013, amounted to 16926.8 per 100000 population of children aged 0-14 years (The Ministry of Healthcare of the Republic of Kazakhstan, 2014).

It is known that children with intellectual disabilities have health problems are more likely than children with normal development (Schrojenstein Lantman-de Valk, Veenstra, Straetmans, Metsemakers \& Curfs, 2008). This is due to the fact that their basic pathology has very complex nature. Usually intellectual impairment of children is a result of a breach of normal development of fetus in utero. This is due to hereditary diseases or random teratogenic influences on the fetus. Most genetic disorders called the syndrome, because they are characterized by multiorgan pathology of various organs and systems, by presence of congenital malformations and by dysplasia. All of these characteristics of children with intellectual disabilities predispose their organisms to development of chronic diseases (Birenbaum, 2010). Also, children with intellectual disabilities often have concomitant psychiatric disorders in the emotional-volitional sphere, convulsions (Frey \& Temple, 2008). Along with comorbid medical problems, children with intellectual disabilities have comorbid psychopathology and comorbid challenging behaviors (Matson \& Cervantes, 2013). Comorbidities in children with intellectual disabilities is reflected in the somatic status affects the performance of physical health. The reconceptualization of health and disability examines health disparity in terms of the determinants of health (genetic, social circumstances, environment, individual behaviors, health care access) and types of health conditions (associated, comorbid, secondary) (Krahn, Hammond, \& Turner, 2006). Children with intellectual disabilities are more prone to colds, often with the formation of foci of chronic inflammation (World Health Organization: The Regional Office for Europe, 2010). In connection with a reduction in the health of children with intellectual disabilities, they require more attention and improve the organization of health care (Allerton, Welch, \& Emerson).

In the literature one can find examples of the multi-center study of people's health condition with intellectual disabilities. They point that necessary to study and monitor health indicators of this people's category. Inclusion of people with intellectual disabilities in the massive public health research is very important as an important mechanism to identify health differences among this population. Despite the presence of a significant amount of scientific evidence of the existence of differences between the health of children with intellectual disabilities and their peers, they are almost always excluded from the mass monitoring of public health. Therefore, these rare studies are very important (Martínez-Leal et al., 2011). These can, for example, consider the following indicators of Health Status:

Body Mass Index;

Oral Health;

Sensory Impairments;

Mobility Difficulties;

Co-Morbidity and others.

Also estimated the determinants of health such Health Determinants, as:

Physical activity;

Lifestyle Indicators;

Challenging Behaviour;

Medication.

Such studies are very important because they provide an opportunity to understand more about the physical and mental health of people with intellectual disabilities. Such data will help experts to develop effective measures to provide persons with intellectual disabilities the same chance to spend a good, healthy life, as well as all other people.

Caring for children with intellectual disabilities means adjusting standard approaches to gathering information on 
children's conditions and symptoms, including good knowledge of relevant risk factors, awareness of atypical presentations to diagnostic screenings and appropriate methods of treatment, care and referral (World Health Organization: The Regional Office for Europe, 2010).

The role of family and carers in this process is crucial. They are an important source of information, as they are in a unique position to observe changes in the child's behaviour and how they may be related to environmental influences. They also play an important role in implementing and monitoring treatment (MENCAP, 2004). If such knowledge and skills are absent, the health needs of children with intellectual disabilities may remain unmet and there may be unnecessary referrals to secondary or tertiary services because primary health care workers are not comfortable treating children with disabilities within the primary health care system. It is crucial that communication with carers be fostered and their views respected.

The services involved include health promotion, primary health care services and specialist health services, when required, but preventive and early intervention services are especially important.

Children, adolescents and adults with intellectual disabilities experience higher rates of many treatable health conditions compared to the mainstream population. Three Australian randomised controlled trials found high levels of unmet health needs in Australian adolescents and adults with intellectual disability. These finding confirmed the community based population surveys of children and adolescents and adults with intellectual disabilities which demonstrates high levels of unrecognised and/or poorly managed physical and mental health conditions.

Provision of health services for people with ID typically take substantially longer and require the involvement of more than one health professional than standard models of care. The presence of comorbid health conditions only partially explains the difference in health service usage, suggesting that other characteristics of this group of people influence the nature and frequency of health services access. Potentially, health system characteristics may also contribute to this difference (Small \& Lennox, 2014).

Person characteristics that may impact health service usage include:

a) Difficulties with verbal communication;

b) Reliance on formal and informal careers for meeting health care needs;

c) Need for others to support decision making and provision of consent;

d) Needs for assistance to participate in community access and leisure activities that might restrict healthy lifestyles, e.g. adequate activity:

1) Limited literacy skills;

2) Inability to recall personal health information such as past major disease, operations or health interventions.

Health system characteristics that may impact health service usage include:

a) Attitudes towards people with ID;

b) Limited skills with adapting communication styles or use of augmented communication strategies;

c) Short consultation times that don't allow for adequate time for explanation;

d) Fragmentation of within health services and with other services;

e) Minimal availability of easy to read health literature.

However, it important to note that works listed in the scientific literature are mainly devoted to the study of the health status of adults with intellectual disabilities, while not enough work, reflecting health's state of children in this category.

The aim of our research was to determine the types of comorbidities and their frequency in children with intellectual disabilities.

To achieve the goal we set ourselves following tasks:

1) Distribute the children into groups of health.

2) Select comorbid diagnoses of children and to analyze them.

\section{Material Studied}

The research was conducted on the basis of a specialized complex "Zhanuya" for children with intellectual disabilities in Almaty. Were examined 73 primary school students. A primary diagnosis of all children was (F70 
Mild mental retardation) according to International Classification of Diseases 10th Revision (ICD-10).

\section{Methods}

In the research, we analyzed the medical records of children with intellectual disabilities, paying attention to health group, primary and comorbid diagnoses. Comprehensive assessment of children's health is carried out by several criteria:

I criterion-presence or absence of abnormalities in early ontogenesis,

II criterion-level of physical development and degree of harmony,

III criterion-level of mental development,

IV criterion-body resistance,

$V$ criterion-functional state of organs and systems,

VI criterion-presence or absence of chronic diseases or congenital malformations.

According to these criteria, the following groups of health:

First (I) group of health-children without deviations on all criteria, which were elected for the evaluation of health; who never sick during the observation period; with the lag in psychological development not more than 1 epikrisis term; as well as children with single morphological abnormalities, which do not affect the condition of child health and does not require correction.

Second (II) group of health-also healthy children, but with the "risk" of developing chronic diseases. At an early age was decided to allocate 2 subgroups among children from the second group of health.

II A group-children with deviations only by first criterion, that is, who have biological, genealogical or social anamnesis, but no abnormalities on all other health criteria.

II B group-children who have some functional and morphological changes, often ill children (4 or more times per year), children with anomalies of constitution and other health deviations.

Third (III) group of health-sick children with presence of chronic diseases or congenital abnormalities in condition of compensation.

Fourth (IV) group of health-children with chronic diseases, congenital malformations in condition of subcompensation.

Fifth (V) group of health-children with serious chronic illness, severe congenital malformations in state of decompensation.

\section{Results}

\subsection{Children's Groups of Health}

The medical records of 73 primary school students were analyzed (Table 2).

Table 2. Classification of pupils according to classes

\begin{tabular}{llcl}
\hline \multirow{2}{*}{ Pupil's class } & \multicolumn{2}{l}{ Number of children } & Girls \\
\hline Preschool group & All & Boys & 5 \\
Zero class & 12 & 7 & 4 \\
First class & 15 & 11 & 6 \\
Second class & 16 & 10 & 10 \\
Total & 30 & 20 & 25 \\
\hline
\end{tabular}

Table 3. Children's health groups

\begin{tabular}{lllll}
\hline \multirow{2}{*}{ Children's class } & \multicolumn{2}{l}{ Group of health } & III & IV \\
\hline Preschool group & I & II & 5 & - \\
Zero class & - & 7 & 1 & - \\
First class & - & 14 & 3 & 2 \\
Second class & - & 11 & 16 & - \\
TOTAL & - & 14 & $25(34 \%)$ & $2(3 \%)$ \\
\hline
\end{tabular}


The average age of all studied children was 7.7 years, of which the average age of children in pre-school group was equal to 6.2 years; 0 class- 7.5 years; 1 class- 8.3 years; in second class- 8.9 years. The number of boys were more than number of girls almost 2 times, that is equal to the ratio of $2: 1$.

Distribution of children into groups of health is presented in Table 3. As we can see from the table, among the observed children mainly there were children who belong to the second and third groups of health, or rather, in many cases there were children of second group of health.

According to the literature, there are many children without intellectual disability of second group of health. For example according to some authors $69.6 \%$ of primary school children without disabilities in development belong to the second group of heath and only $7.8 \%$ of them belong to the III group, while children of the IV group of health don't occur (Paranicheva \& Tyurina, 2012). In our study, despite the fact that generally there were children of the second group of health, it should be noted that the number of children with the third group of health was about $34 \%$ and this was much higher compared with children without intellectual disability (7.8\%), as it was published in literature. In addition, $3 \%$ of surveyed children belong to the fourth group of health, the diagnosis of these two children was "Cerebral Palsy".

\subsection{Description of Neurological Abnormalities in Children}

Twenty four children (33\%) with intellectual disabilities were with Significant neurological abnormalities. There were neurological pathologies of various nature (Table 4).

Table 4. Description of neurological disorders in children

\begin{tabular}{lll}
\hline $\mathbf{N o}$ & Neurological pathology & Number of children (\%) \\
\hline $\mathbf{1}$ & Hypertension-hydrocephalic syndrome & 12 \\
$\mathbf{2}$ & Microcephaly & 4 \\
$\mathbf{3}$ & Inorganic enuresis & 3 \\
$\mathbf{4}$ & Hydrocephalus & 2 \\
$\mathbf{5}$ & Hemiparesis & 1 \\
$\mathbf{6}$ & Convulsions & 1 \\
$\mathbf{7}$ & Asthenic-nervous syndrome & 1 \\
Total & & $24(33 \%)$ \\
\hline
\end{tabular}

According to the data presented in the table, hypertension-hydrocephalic syndrome was defined in most cases. More severe forms of disease, such as microcephaly, hydrocephalus, convulsions, hemiparesis, inorganic enuresis were relatively rare.

Disorders in the emotional-volitional sphere were detected in 9 (12\%) children; attention deficit disorder and hyperactivity were detected in 4 children; sleep disorders in 3 children; one child with psychopathic syndrome and one child with emotional instability.

\subsection{Comorbidities in Children}

Comorbidities were registered in $48(66 \%)$ children with intellectual disabilities, which is about $2 / 3$ of all surveyed children. Accordingly, only remaining 25 (34\%) children had no comorbidity. It is typical for children with intellectual disabilities and is consistent with the literature. This is partly due to the presence of congenital anomalies of organs and systems as a result of hereditary diseases or embriofetopaty. The variety of concomitant diagnoses can be seen in Table 5 .

Thus, the data in Table indicate that 34 species of disease entities were identified and were defined in 64 cases. Diseases associated with chronic inflammation detected most frequently. It is well known that the presence of chronic foci of infection in the body indicates a decline in immunity. TB infection has also been attributed to this group, as characterized by chronic intoxication. It should be noted that in general, incidence of tuberculosis in the region is relatively high. Also it should be noted that relatively wide distribution of endemic goiter is associated with iodine deficiency in our region.

According to the presented data, the bulk of identified diseases consists of congenital malformations and defects of cardiovascular, genitourinary, musculoskeletal system, hearing and sight. In 11 (15\%) of all surveyed children with intellectual disabilities were identified complex defects, it is a combination of two or more kinds of vices. Among them, 2 cases generated considerable interest, so we decided to describe them in more detail:

1) M. is a 6 year old boy of pre-school group and the third group of health. He is often ill child. Primary 
diagnosis: residual-organic lesion of the central nervous system, (F70 Mild mental retardation). Comorbid diagnoses: congenital heart disease (patent foramen ovale), atrial septal defect, hydronephrosis of the left kidney, secondary chronic pyelonephritis, recurrent obstructive bronchitis, chronic sinusitis, biliary dyskinesia, TB infection, iron deficiency anemia of the first degree.

2) A. is a 7 year old boy of pre-school group and the third group of health. Primary diagnosis: residual-organic lesion of the central nervous system, (F70 Mild mental retardation). Comorbid diagnoses: atresia of the external auditory canal, microtia, bilateral sensorineural hearing loss, congenital heart disease (patent foramen ovale, circulatory failure 0, aortic stenosis).

Table 5. Description of additional abnormalities in children

\begin{tabular}{|c|c|c|}
\hline № & Types of additional pathologies & Amount \\
\hline & Chronic inflammatory diseases: & 20 \\
\hline 1 & Infected with tuberculosis & 8 \\
\hline 2 & Chronic sinusitis & 3 \\
\hline 3 & Chronic pyelonephritis & 3 \\
\hline 4 & Adenoids & 3 \\
\hline 5 & Chronic tonsillitis & 2 \\
\hline \multirow[t]{2}{*}{6} & Chronic obstructive bronchitis & 1 \\
\hline & Congenital heart defects and diseases: & 12 \\
\hline 7 & Patent foramen ovale & 5 \\
\hline 8 & Atrial septal defect & 3 \\
\hline 9 & Myocardiodystrophy & 1 \\
\hline 10 & Pulmonary stenosis & 1 \\
\hline \multirow[t]{2}{*}{11} & Aortic stenosis & 2 \\
\hline & Diseases of view: & 10 \\
\hline 12 & Amblyopia & 5 \\
\hline 13 & Optic atrophy & 1 \\
\hline 14 & Hypermetropia & 1 \\
\hline 15 & Horizontal nystagmus & 1 \\
\hline 16 & Blepharoptosis & 1 \\
\hline \multirow[t]{2}{*}{17} & Compound myopic astigmatism & 1 \\
\hline & Shortages: & 7 \\
\hline 18 & Endemic goiter & 4 \\
\hline \multirow[t]{2}{*}{19} & Iron deficiency anemia & 3 \\
\hline & Malformations of the urogenital organs: & 6 \\
\hline 20 & Cryptorchism & 2 \\
\hline 21 & Hypoplasia of the testes & 1 \\
\hline 22 & Anomalies of the kidneys & 1 \\
\hline 23 & Hydronephrosis & 1 \\
\hline \multirow[t]{2}{*}{24} & Inguinal hernia & 1 \\
\hline & Pathology of the musculoskeletal system: & 6 \\
\hline 25 & Flatfoot & 3 \\
\hline 26 & Physical disorders & 2 \\
\hline \multirow[t]{2}{*}{27} & Funnel chest & 1 \\
\hline & Diseases of the gastrointestinal tract: & 6 \\
\hline 28 & Biliary dyskinesia & 4 \\
\hline \multirow[t]{2}{*}{29} & chronic cholecystitis & 2 \\
\hline & Congenital hearing loss: & 4 \\
\hline 30 & Deafness & 2 \\
\hline 31 & Microtia & 1 \\
\hline \multirow[t]{2}{*}{32} & Atresia of the external auditory meatus & 1 \\
\hline & Diseases of the skin: & 3 \\
\hline 33 & Atopic dermatitis & 2 \\
\hline 34 & Hemangioma of forehead skin & 1 \\
\hline \multicolumn{2}{|c|}{ Grand Total } & 64 \\
\hline
\end{tabular}


All examined children are on dispensary registration and regularly are observed by medical staff of school, systematically take health and rehabilitation courses in specialized medical and sanatorium establishments.

\section{Conclusion}

To summarize, we can conclude that children with intellectual disabilities in addition to neurological disorders often have congenital and acquired diseases of various organs and body systems. This leads to reduction of immunity, development of chronic inflammatory diseases. All of this require special attention to the health of this category children and comprehensive measures to strengthen and improve health. Formation of healthy lifestyles among children with intellectual disabilities is also very important, to unite them for working together in this direction.

\section{References}

Allerton, L. A., Welch, V., \& Emerson E. (2011). Health inequalities experienced by children and young people with intellectual disabilities: A review of literature from the United Kingdom. Journal of Intellectual Disabilities, 15(4), 269-278. http://dx.doi.org/10.1177/1744629511430772

Birenbaum, A., Children, Disability, \& Chronic Care. (2010). Intellectual and Developmental Disabilities, 48(5), 393-395. http://dx.doi.org/10.1352/1934-9556-48.5.393

Frey, G. C., \& Temple, V. A. (2008). Health promotion for Latin Americans with intellectual disabilities. Salud Publica Mex, 50(2), 167-177. http://dx.doi.org/10.1590/S0036-36342008000800010

Jacqueline, S., \& Nick, L. (2014, July 25). Submission to Independent Hospital Pricing Authority by the Australian Association of Developmental Disability Medicine. Retrieved from http://www.ihpa.gov.au/

Johnny, L. M., \& Cervantes, P. E. (2013). Comorbidity among persons with intellectual disabilities. Research in Autism Spectrum Disorders, 7(11), 1318-1322. http://dx.doi.org/10.1016/j.rasd.2013.07.018

Krahn, G. L., Hammond, L., \& Turner, A. (2006). A cascade of disparities: Health and health care access for people with intellectual disabilities. Ment Retard Dev Disabil Res Rev, 12, 70-82. http://dx.doi.org/10.1002/ mrdd.20098

Lantman-de Valk, H. A. S., Veenstra, M., Straetmans, J., Metsemakers, J., \& Curfs, L. (2008). Health management for people with intellectual disabilities in primary care; impact on basic physical functions. Journal of Intellectual Disability Research, 52(10), 812-812. http://dx.doi.org/10.1111/j.1365-2788.2008. 01119_4.X

Martínez-Leal, R., Salvador-Carulla, L., Linehan, C., Walsh, P. N., Weber, G., Van Hove, G., ..., Kerr, M. P. (2011). The Impact of Living Arrangements in the Health Status of Persons with Intellectual Disability in Europe: An observational study using a health survey in 14 European countries. Journal of Intellectual Disability Research, 55(9), 858-872. http://dx.doi.org/10.1111/j.1365-2788.2011.01439.x

MENCAP. (2004). Treat I right! Better health care for people with learning disability. London, MENCAP.

Paranicheva, T. M., \& Tyurina, E. V. (2012). Health trends preschool and primary school age. New research: Health and physical development, 4(33), 68-78. Scientific Library Kiber Leninka. Retrieved from http://cyberleninka.ru/

The Ministry of Healthcare of the Republic of Kazakhstan. (2014). Health of the Republic of Kazakhstan and activities of public health organizations in 2013: Statistical compilation. Astana: The Ministry of Healthcare of the Republic of Kazakhstan. Retrieved from http://www.mzsr.gov.kz/sites/default/files/2013_0.pdf

World Health Organization. (2010). Better health, better lives: Children and young people with intellectual disabilities and their families. Bucharest, Romania, 26-27 November 2010 EUR/51298/17/5.-6 September 2010. World Health Organization: The Regional Office for Europe. Retrieved from http://www.euro.who. int/intellectual_disabilities

\section{Copyrights}

Copyright for this article is retained by the author(s), with first publication rights granted to the journal.

This is an open-access article distributed under the terms and conditions of the Creative Commons Attribution license (http://creativecommons.org/licenses/by/3.0/). 